\title{
RECURRENT LUMBAR DISC HERNIATION OUTCOME ANALYSIS OF REPEAT DISCECTOMY
}

\author{
Kalevski S. \\ Department of Neurosurgery, ENT and Ophthalmology, Varna Medical University
}

Reviewed by: Assoc. Prof. N. Deleva

\begin{abstract}
BACKGROUND CONTEXT: Recurrent lumbar disc herniation is the most common reason for unsatisfactory results following disc excision and it occurs in $2 \%$ to $13 \%$ of surgically treated patients. There have been many studies on recurrent disc herniation, but these studies often reviewed recurrence along with other causes of failed disc surgery. Specific studies on long-term outcomes of the repeat discectomy are relatively lacking in the literature. PURPOSE: To investigate the long-term functional outcomes of the repeat discectomy using ODI and VAS, and the risk factors of recurrent disc herniation. STUDY DESIGN: A prospective evaluation of 21 patients with recurrent disc herniation. PATIENT SAMPLE: All of the 21 patients selected for the study have at least one reoperation for recurrent disc herniation. OUTCOME MEASURES: The outcome is measured using VAS and ODI questionnaires filled in by the patients themselves. METHODS: Recurrent disc herniation was defined as disc herniation at the same level (ipsilateral or contralateral) and disc herniation at a different level, with pain-free interval greater than 1 month. The levels of disc herniation were: L2-L3 ( 1 case), L3-L4 (1 case), L4-L5 ( 9 cases), L5-S1 (9 cases), two levels L4-L5 and L5-S1 (1 case). Nine men and 12 women of mean age 43.7 (18-57) years were studied. In order to evaluate the pain syndrome and functional impairment, we used the visual analog scale (VAS) $0-\mathbf{- 1 0 0} \mathbf{~ m m}$ and Oswestry Disability Index (ODI) 2.0 before the initial surgery, before the reoperative surgery, as well as on follow-ups after the first and sixth month, first year, and after five and more years. RESULTS: A group of 489 consecutive patients with primary discectomy is investigated. We identified sixty-four patients $(\mathbf{1 3 . 0 9 \% )}$ reoperated for a variety of reasons (including complications). Out of the whole group of the reoperated, 21 patients $(32.8 \%)$ with $\mathrm{RDH}$ are selected. There is a tendency of deterioration that is reflected by the ODI values that range from 10 to $48(31 \%$ mean) after the follow-up that varies from 1 to 8 years $(4.8$ mean). Nevertheless, only two of the patients $(9.5 \%)$ are not satisfied with the treatment altogether. The two patients claim that the results after the treatment do not meet their expectations before the initial discectomy. CONCLUSIONS: In the group that we investigated for a long enough time (mean of 4.8 years follow-up), $4,3 \%$ of the patients with primary discectomiy are reoperated due to RDH. Only 2 of the patients $(9.5 \%)$ had unsatisfactory results after the reinterventions. The age, gender, preoperative symptoms, life style or the occupation are not recognized as factors that could increase the risk of RDH. Only disc protrusions require reinterventions due to RDH three times more frequently than primary extrusions or sequestrations.sions require reinterventions due to RDH three times more frequently than primary extrusions or sequestrations.
\end{abstract}

Key words: recurrent lumbar disc herniation, reoperations, Oswestry Disability Index, Visual Analog Scale, lumbar disc surgery, revision surgery, outcome study

\section{BACKGROUND}

Lumbar discectomy is an effective method for $75-90 \%$ of patients suffering from lumboradiculalgia resistant to the conservative treatment (10). However, despite the advancement in diagnostics and surgical procedures, $10-20 \%$ of the patients $(15,23,26)$ (according to other authors

Address for correspondence:

Sv. Kalevski, Dept. of Neurosurgery, ENT and Ophthalmology

Medical University, BG-9002 Varna, Bulgaria, 55 Marin Drinov str. e-mail:dr_kalevski@abv.bg
$20-40 \%(1,3,4,8,11,14,16,21,24)$ had dissatisfactory or bad postoperative results and further reoperative treatment was necessary.

Many authors have investigated the reasons for these dissatisfactory results, but their conclusions are often contradictory. The reasons that are commonly emphasized are inadequate neural decompression, recurrent disc herniation (RDH), underestimated associated lateral or central stenosis, wrong level of operation, bad patient selection, epidural and epineural fibrosis, arrachnoiditis, segmental instability, 
Kalevski S. K.

facet joint disease, nerve root injury, infectious complications, dural tear, etc. $(5,6,8,11,13-16,21,23,24)$

Occurring in 2-13\% of the patients with persisting and recurring lumboradiculalgia $(11,18,23)$, RDHs are the most common reason for unsatisfactory postoperative results. The RDH could be located at the level of the initial surgery - ipsilaterally or contralaterally, or at a different level (3-6,8, $12,13,18,23,24)$. If the syndrome of lumboradiculalgia recurs several pain-free months after the initial discectomy, the most probable diagnosis is $\mathrm{RDH}$.

Furthermore, many authors prove that the reoperative surgery for RDH yields good results that are comparable to the results from the initial discectomy $(3,4,12,18,23)$.

An accurate preoperative diagnosis and meticulous following of the surgical procedure are crucial for the successful treatment of RDH.

The goals of this research are: to analyze the functional results of a group of reoperated RDH patients; to identify the factors that have a negative influence on these results; and to assess the patient's satisfaction with their surgeries when compared to their expectations before their initial discectomy.

\section{MATERIAL AND METHODS}

For a period of 1-8 years (mean 4.8), 21 patients with repeat discectomy are followed. All of the patients have initial microdiscectomy, using the standard open interlaminar Yasargil , Caspar and Loew approach that is comprised of limited unilateral laminotomy, medial arthrectomy and disc enucleation through a small posterolateral rectangular incision of annulus fibrosus. All of the patients have at least one reoperation for $\mathrm{RDH}$.

In the final stage of the operative procedure the neural structures are isolated from the adjacent tissues using autograft fat tissue, fixed to the paraspinal muscles. The 21 patients ( 9 men and 12 women with mean age of 43.4 years) under observation are a subgroup, presenting 32.8\% of a bigger group of 64 patients reoperated for a variety of reasons. The whole cohort of 64 reoperated patients is a subgroup selected from a bigger group of 489 patients that had undergone primary lumbar discectomy. Among these patients, all of whom were treated in one hospital, 254 $(51.9 \%)$ are men and $235(48.1 \%)$ are women, with mean age of 44.3 (17-74) years. The subgroup of the patients with $\mathrm{RDH}$ is comprised of those who have recurrent disc herniation at the operated level (ipsilateral or contralateral) or at an adjacent level. It has been proven that the levels adjacent to the herniated disk are exposed to additional load that causes an accelerated degenerative process, hence the rupturing of annulus fibrosus. Thus, we believe that the adjacent level should also be considered in respect to RDH. This is the reason why the herniated disk at adjacent level, termed "de novo" disc herniation by some authors, is directly related to the primary discectomy $(5,6,8,12,20,27)$. Furthermore, the recurrence of the pain syndrome and deterioration of the functional status of the patient that has al- ready undergone initial lumbar surgery often necessitates another surgical procedure, even though it is preformed to another level.

We define one month to be the minimal period of of pain relief, as after the sixth month the formation of epidural fibrosis becomes a normal occurrence and contributes to the pain. The patients with associated foraminal stenosis or massive epidural fibrosis are excluded from the investigated group.

Lumbalgia or/and severe radicular pain that do not respond to conservative management and at least for more than six weeks and $\mathrm{DH}$ with compression of nerve root confirmed by $\mathrm{CT}$ or MRI are considered as indications for the initial surgery.

All the patients of the investigated group show positive stretching phenomena (less than 60 degree) and loss of sensation in the corresponding to the affected nerve root dermatome. Some of the patients also show hypotonia of the affected myotome of the affected muscles, as well as loss of tendon reflexes.

Two of the patients had bladder dysfunction. The diagnosis is based on MRI or CT findings and is confirmed with the intraoperative findings. The indications for reoperative surgery are similar to those taken into consideration for the initial surgery. The findings from the clinical examination of the patients that are considered for the reoperative surgery are supplemented to the findings from the initial surgery. All recurrent disc herniations are confirmed with MRI without contrast enhancement and with CT (Fig. 1).

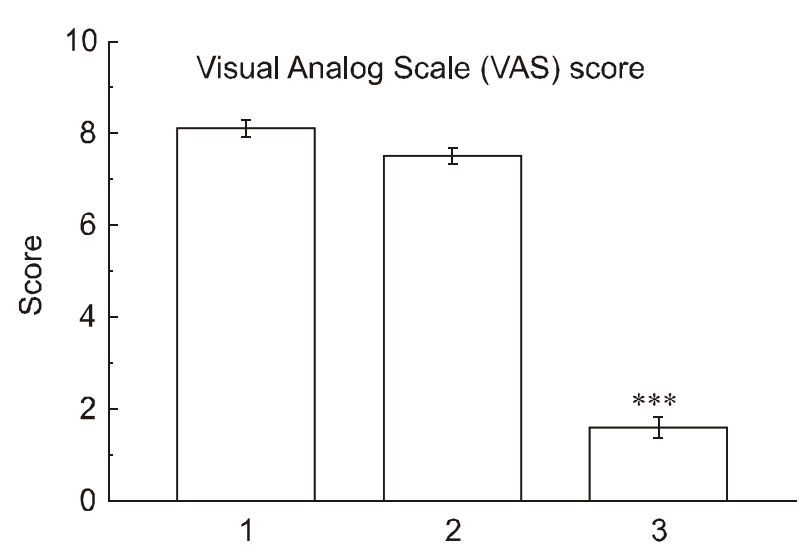

Fig. 1. Visual Analog Scale (VAS) score of 21 patients. 1 = before primary discectomy, 2 = before reinterventions, 3 = after a 5-year follow-up. ***, $P$ ? 0,001 (Kruskal-Wallis test or Tukey-Kramer pair-wise comparisons).

The same standard open discectomy is used for the redo interventions, respecting the rules of the reoperative spinal surgery. In order to evaluate the pain syndrome and functional impairment, we use the visual analog scale (VAS) 0 $-100 \mathrm{~mm}$ (21) and Oswestry Disability Index (ODI) 2.0 before the initial surgery, before the reoperative surgery and on follow-ups. The patients manually fill out the VAS and ODI questionnaires. The ODI questionnaire is an instrument that is comprised of ten questions, each with six possible answers that reflect the everyday activity of the patients. 
It is the most universal questionnaire that affords precise assessment of the effectiveness of the implemented treatment. Furthermore, it is also possible to make deductions for the quality of life, as the test-retest with SF-36 is $0.99(7,14)$. The answers to the questions are evaluated on a scale from 0 to 5 , where 5 points is the highest value of possible functional impairment. The maximum total of the questionnaire is 50 points. A score of $0-10$ points refers to minimal functional impairment, 11 - 20 points corresponds to moderate impairment, 31 - 40 - to severe disability. A score of 41 - 50 points refers to bed-ridden patients.

The scores in points are transformed in percent by dividing by 5 and multiplying by 10 .

The same questionnaires are filled out on the follow-ups after the first and sixth month, first year, and after five and more years.

The subjective evaluation of the treatment outcome is compared with the expectations of the patients. Each case is marked with "yes" or "no" according to the patient's satisfaction with the treatment.

We use the following statistical methods in order to objectify the results.

\section{Statistical Analysis}

Stastical significance of VAS and ODI data was evaluated using nonparametric tests (Mann-Whitney $\mathrm{U}$ test and Kruskal-Wallis test) or one-way ANOVA followed by Tukey-Kramer's post hoc comparisons. Data was expressed as means \pm s.e.m. Differences were considered significant when $\mathrm{P}<0.05$.

\section{RESULTS}

A group of 489 consecutive patients with primary discectomy was investigated. Multilevel disc herniations were found in $12(2.45 \%)$ of them (11 patients with herniations on two levels and 1 on three levels). Sixty-four patients $(13.09 \%)$ were reoperated for a variety of reasons (including complications). Out of the whole group of the reoperated, 21 patients $(32.8 \%$ ) with RDH are selected - one on level L2-L3, one on L3-L4, 9 on L4-L5 and 10 on L5-S1. One reoperative procedure was performed in a subgroup of 18 patients and 3 patients underwent two reoperations (one with RDH, one with infection and one with cerebro-spinal fluid leak). The cumulative risk for RDH for a period of approximately five years is estimated at $4.3 \%$.

The primary discectomy in the investigated group was preformed on the following levels: L2-L3 - 1 patient; L3-L4 1 patient; L4-L5 - 9 patients and L5-S1 - 9 patients. One patient has primary discectomy on two levels: (L4-L5 and L5-S1). Disc protrusions were found in 16 cases, extrusions - in 4 cases and sequestrations - in 1.

Through the reoperative procedures, we found 11 (52.4\%) ipsilateral RDHs, 7 (33.3\%) contralateral RDHs and 3 $(14.3 \%)$ at adjacent level $\mathrm{RDH}$. The period of pain relief is found to be 1- 54 months (mean $22 \mathrm{~m}$ ). The duration of the pain syndrome due to nerve root compression is mean 3.8 months (7 days - $14 \mathrm{~m})$ - before the primary discectomy, while before the reintervention it is 2.4 months $(1 \mathrm{~m}-8 \mathrm{~m})$. While $13(61.9 \%)$ of the patients relate the reappearance of recurring pain to a physical exertion or trauma, the rest claim that the pain syndrome had returned gradually.

Five patients had a 1-6 month pain-free interval, 10 patients were pain-free for up to 2 years, and 6 patients for over two years. The strength of the pain before the primary discectomy was 8.1 mean, according to VAS and 7.5 mean before the reinterventions. (Fig. 2).

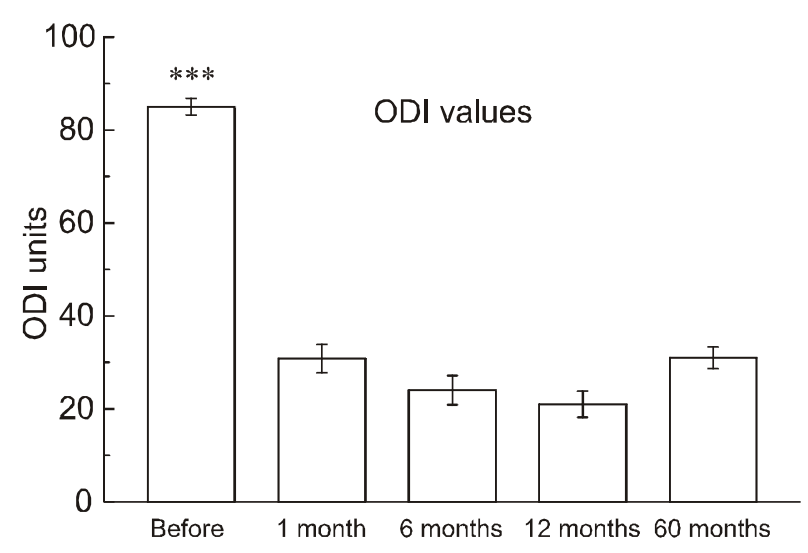

Fig. 2. ODI score of 21 patients before operation or after operation at 1, 6, 12, and 60 month time-points. ***, $P \leq 0,001$ (Kruskal-Wallis test or Tukey-Kramer pair-wise comparisons).

After mean of 5 years, the score at the follow-up was 1-4 points (1.6 mean).

It is notable that the extent of herniation is related to the kind of the RDH. All of the contralateral RDHs (n-7) are considered to be a result of primary disc protrusion, while $2 / 3$ of RDHs at adjacent level are due to extrusions and 1/3 is due to sequestration. The 11 ipsilateral RDHs are due to 9 protrusions and 2 extrusions. All of the patients had disc compression of the corresponding nerve root that is associated with limited or moderately developed epidural fibrosis, which necessitated limited adhesiolisis and caudally elongated laminectomy in 14 of the studied patients.

Within a period of several months (3-7) three patients underwent a second reintervention. The first patient was diagnosed with retained disc fragment. The intraoperative finding was a retained disc fragment compressing the caudal part of the nerve root canal. A deep wound infection intractable to the conservative treatment was the reason for the reintervention of the second patient.

Pseudomeningocele due to unrepaired incidental dural tearing was the reason for the reintervention in the third patient.

None of the reoperated patients had segment instability, thus, none of the patients had stabilization procedures (arthrodesis).

\section{Surgical results}

One month after the reintervention 16 patients $(76.2 \%)$ had excellent or good results - before the reintervention ODI is mean 
Kalevski S. K.

$85 \%$ (90 - 55), while after the reoperation ODI improved to mean $26 \%$. The rest of 5 patients $(23.8 \%$ ) have mean improvement - ODI $46 \%$ and have persisting of the complaints.

On the sixth month, ODI is mean $24 \%$, while $17(81 \%)$ of the patients are with good and excellent results and are satisfied with the treatment and the achieved functional status. After one year follow-up, ODI is $21 \%$ mean, while $90.5 \%$ (19/21 patients) are satisfied after the treatment was undertaken. After the follow-up varying between 1 and 8 years ( 4.8 mean), there is a tendency of deterioration that is reflected by the ODI values that range from 10 to 48 ( $31 \%$ mean).

Nevertheless, only two of the patients $(9.5 \%)$ are not satisfied with the treatment altogether. The two patients claim that the results after the treatment do not meet their expectations from before the initial discectomy (Fig. 3).

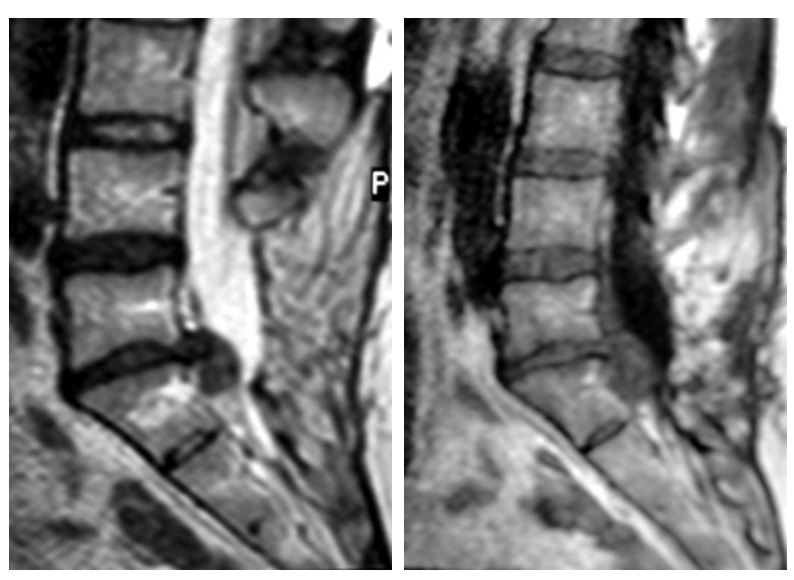

Fig. 3. T2 and T1 weighted MRI images demonstrating big left-sided retained disc fragment on L5-S1 level of 43-years old patient with persisting postoperative pain syndrome three months after the primary discectomy.

\section{DISCUSSION}

RDHs are one of the most common reasons for reinterventions. They were found in $2-13 \%(2,19,20,23)$ of the patients reoperated after lumbar disc surgery and are considered to be a reason for reintervention in $12.4-76 \%$ of all reoperated patients $(3,12,19,22)$.

After a 5-year follow-up, we found that RDHs comprise $4.3 \%$ of all primary discectomies. As a reason for recurrent complaints and reinterventions, RDHs are $32.8 \%$ of all reoperated patients. Approaching the problem mechanically, many authors $(2-5,9-11,17,21,23,24)$ try to strictly define $\mathrm{RDH}$ by calling it "true RDH". Thus, they confine it to a presence of disc material on the same side or contralaterally at the operated level that is found after a minimum of 6 months pain-free interval after the primary discectomy.

Like many other authors $(6,8,12,19,20)$, we approach the RDH clinically. However, we also consider the point of view of the patients, who go through another surgical procedure due to the same or similar complaints.

This is the reason why when considering $\mathrm{RDH}$, we also include the "de novo" DH (6) that is at the adjacent to the ini- tial discectomy level, especially when the risk of reinterventions is evaluated during the prolonged follow-up. It is well known that after disc enucleation, the adjacent segments are subjected to extra load, hence accelerated degenerative changes. The latter is a normal attendant of the progressing degenerative disease and demands additional specific treatment.

Papadopoulos et al. (18) investigated the clinical results of a group of 27 patients with two months pain-free period, reoperated due to RDH on the same level and side as the initial discectomy. The results are confronted with the results of another group of 30 patients with primary discectomy. The two groups were followed-up for a long enough period of time - 53.6 months mean for the one group and 40.9 months mean for the other one. The gained satisfactory results based on the filled in questionnaires from the patients of the groups are comparable (According to the patients' answers in the questionnaires, the results of the two groups are comparable/ similar); therefore, the authors recommend repeated discectomy to treat patients with $\mathrm{RDH}$.

Cinotti et al. $(3,4)$ prospectively analyzed groups of patients with $\mathrm{RDH}$ on the same level, ipsilateral or contralateral to the primary discectomy side. They found that there is no difference between the functional status of patients operated once and those that were reoperated.

Suk et al. (23) and Dai et al. (5) in their studies come up with similar results, as they do not succeed in establishing factors that negatively influence the results from the reinterventions.

Erbayraktar et al. (6) follow the results of 14 patients with $\mathrm{RDH}$. Five of the patients are with RDH at another level. Based on the good results that were obtained, they recommend reoperative treatment of the patients with $\mathrm{RDH}$.

Similar results and conclusions were gained by Kayaoglu et al. (12) when they studied a group of 17 reoperated patients with $\mathrm{RDH}$ on the same level and 9 patients with $\mathrm{RDH}$ on another level. $82.4 \%$, of the subgroup of patients with same-level RDH showed excellent and good results in while a $100 \%$ of the patients with RDH at another level had excellent results.

In contrast, Fritsch et al. (8) claim that most of the patients with RDH on the same or another level show unsatisfactory results when followed for a long enough time. Using ODI for following their patients, Skaf et al. (21) observed the best functional results in the subgroup of patients with $\mathrm{RDH}$ among the reoperated patients.

Hakkinen et al. (10) found 17 patients with RDH in a group of 166 patients with primary discectomies that were followed for a period of five years. Of the patients with $\mathrm{RDH}$, $12(71 \%)$ had RDH on the same level and side, while 5 (29\%) had RDH on a different level and side.The authors did not find a relationship between the number of reoperations, age, gender, preoperative symptoms, physical activity and the occupation of the patient (Tabl. 1).

Our results are concordant with those of most of the authors. The functional results that we gained following our patients for a long enough time commensurate with the functional results of the patients with primary discectomies that are 
quoted in the literature. We do not find any factors that increase the risk of RDH. Based on our investigation, we conclude that the primary protrusions are the more common reason for RDH than the extrusions and sequestrations. for other structural reasons, have the best chances to have good results from the treatment. Only $2 / 21$ patients in our investigation with mean of 4.8 years follow-up had unsatisfactory results and regret having undergone the primary discectomy.

Table 1. Overall results of repeat discectomy.

\begin{tabular}{|c|c|c|c|c|c|c|c|c|c|}
\hline & Cinotti (4) & Cinotti (3) & Dai (5) & $\begin{array}{c}\text { Erbayracta } \\
\mathbf{r}(6)\end{array}$ & $\begin{array}{c}\text { Hakkinen } \\
\text { (10) }\end{array}$ & $\begin{array}{l}\text { Papadopoul } \\
\text { us (18) }\end{array}$ & Suk (23) & Wera (26) & Kalevski \\
\hline $\begin{array}{c}\text { Number of } \\
\text { patients } \mathrm{M} / \mathrm{F}\end{array}$ & $\begin{array}{c}26 \\
18 / 8\end{array}$ & $\begin{array}{c}16 \\
10 / 6\end{array}$ & $\begin{array}{c}39 \\
23 / 16\end{array}$ & $\begin{array}{l}14 \\
6 / 8\end{array}$ & $\begin{array}{l}17 \\
8 / 9\end{array}$ & $\begin{array}{c}27 \\
20 / 7\end{array}$ & $\begin{array}{c}28 \\
20 / 8\end{array}$ & $\begin{array}{c}14 \\
10 / 4\end{array}$ & $\begin{array}{l}21 \\
9 / 12\end{array}$ \\
\hline $\begin{array}{c}\text { Ipsilateral } \\
\text { Contralateral } \\
\text { Other level }\end{array}$ & $\begin{array}{c}26 \\
- \\
-\end{array}$ & $\begin{array}{l}- \\
16 \\
-\end{array}$ & $\begin{array}{c}32 \\
7 \\
-\end{array}$ & $\begin{array}{l}9 \\
- \\
5\end{array}$ & $\begin{array}{l}12 \\
5 \\
-\end{array}$ & $\begin{array}{c}26 \\
- \\
1\end{array}$ & $\begin{array}{c}21 \\
7 \\
-\end{array}$ & $\begin{array}{l}6 \\
8 \\
-\end{array}$ & 1173 \\
\hline $\begin{array}{c}\text { L2 - L3 } \\
\text { L3 - L4 } \\
\text { L4 - L5 } \\
\text { L5 - S1 } \\
\text { Multilevels }\end{array}$ & & $\begin{array}{c}- \\
2 \\
11 \\
3 \\
-\end{array}$ & $\begin{array}{c}- \\
1 \\
27 \\
11 \\
-\end{array}$ & & $\begin{array}{l}- \\
- \\
8 \\
8 \\
1\end{array}$ & $\begin{array}{c}1 \\
- \\
12 \\
12 \\
2\end{array}$ & $\begin{array}{c}- \\
- \\
19 \\
9 \\
-\end{array}$ & $\begin{array}{l}- \\
4 \\
6 \\
7\end{array}$ & $\begin{array}{c}1 \\
1 \\
9 \\
10 \\
-\end{array}$ \\
\hline $\begin{array}{c}\text { Mean age at } \\
\text { surgery }\end{array}$ & $\begin{array}{c}47 \\
(27-67)\end{array}$ & $\begin{array}{c}46 \\
(32-67)\end{array}$ & $\begin{array}{c}48 \\
(27-72)\end{array}$ & $\begin{array}{c}46 \\
(30-62)\end{array}$ & $\begin{array}{c}41 \\
(16-74)\end{array}$ & 39,2 & $\begin{array}{c}42,1 \\
(18-64)\end{array}$ & $\begin{array}{c}48,3 \\
(27-83)\end{array}$ & $\begin{array}{c}43,7 \\
(18-57)\end{array}$ \\
\hline $\begin{array}{c}\text { Pain relief } \\
\text { mean }\end{array}$ & $\begin{array}{c}16 \mathrm{~m} \\
(6 \mathrm{~m}-31 \mathrm{~m})\end{array}$ & $\begin{array}{c}4,1 y \\
(1-6,3 y)\end{array}$ & $\begin{array}{c}5 y 4 m \\
(6 m-17 y)\end{array}$ & $(3 m-32 m)$ & & $\begin{array}{c}63,3 \mathrm{~m} \\
(2-252 \mathrm{~m})\end{array}$ & $\begin{array}{c}60,8 \mathrm{~m} \\
(7-168)\end{array}$ & $\begin{array}{c}2,8 \mathrm{~m} \\
(2 \mathrm{~d}-5,5 \mathrm{~m})\end{array}$ & $22 \mathrm{~m}(1-54)$ \\
\hline Follow - up & $24 \mathrm{~m}$ & $24 m$ & $\begin{array}{c}7 y 8 m \\
(1 y-15 y)\end{array}$ & & $5 y$ & $\begin{array}{l}40,9 \mathrm{~m} \\
(9 \mathrm{~m}-6 \mathrm{y})\end{array}$ & $1 \mathrm{~m}$ & $\begin{array}{c}52,6 \mathrm{~m} \\
(15-87)\end{array}$ & $4,8 y(1-8)$ \\
\hline \multicolumn{10}{|c|}{ Rate } \\
\hline VAS & & $5,2-1,5$ & & & & & & & $1,6(0-4)$ \\
\hline ODI & & $17,6-3,9$ & $12(3-18)$ & & & & & & $31(10-48$ \\
\hline \multicolumn{10}{|c|}{ McNab criteria } \\
\hline $\begin{array}{l}\text { Exellent } \\
\text { Good } \\
\text { Fair } \\
\text { Poor }\end{array}$ & $\begin{array}{c}5 \\
17 \\
3 \\
1\end{array}$ & & $\begin{array}{c}29 \\
10\end{array}$ & $\begin{array}{l}8 \\
4 \\
1 \\
1\end{array}$ & & $\begin{array}{c}23 \\
3 \\
1\end{array}$ & & $\begin{array}{l}5 \\
4 \\
4 \\
1\end{array}$ & $\begin{array}{c}16 \\
3 \\
1 \\
1\end{array}$ \\
\hline
\end{tabular}

Morgan-Hough et al. (15) obtain similar results and make similar conclusions - they consider the protrusion as an imminent process of serial fragmentation of the disc material, while the extrusion and sequestration are considered to be the end stage of the process.

Furthermore, considering the process of disc enucleation from a technical point of view, only the last two kinds of disc fragmentation allow the disc enucleation to be fully done. Therefore, there are less residual disc fragments that compress neural structures. We realize that it is very difficult to compare the results of investigations made by different authors, in different times, using different diagnostic tools and operative techniques, different patient selection, follow-up time, etc.

Nevertheless, something practical could be found in every single investigation made by the different authors. Furthermore, there is always a pursuit to reduce the number of the patients that permanently stay with unsatisfactory results in respect to the whole process of performing lumbar discectomy. Therefore, $\mathrm{RDH}$ patients, rather than patients necessitating reintervention

\section{CONCLUSION}

In the group that we investigated for a long enough time (mean of 4.8 years follow up), $4.3 \%$ of the patients with primary discectomy are reoperated due to RDH. Only 2 of the patients $(9.5 \%)$ had unsatisfactory results after the reinterventions. The age, gender, preoperative symptoms, life style or the occupation are not recognized as factors that could increase the risk of RDH. Only disc protrusions require reinterventions due to $\mathrm{RDH}$ three times more frequently than primary extrusions or sequestrations.

\section{REFERENCES}

1. Atlas SJ, Keller RB, Chang Y, Deyo RA, Singer DE. Surgical and nonsurgical management of sciatica secondary to a lumbar disc herniation. Five-year outcomes from the Maine Lumbar Spine 
Kalevski S. K.

Study. Spine. 2001; 26(10):1179-1187.

26(10):1179-1187.

2. Abla AA, El Kadi M, Bost J, Maroon JC, Wert M. Recurrent Lumbar Disc Herniation: Microsurgical Approach. Contemporary Spine Surgery. 2005;6 (10):1-6.

3. Cinotti G, Gumina S, Giannicola G, Postacchini F. Contralateral Recurrent Lumbar Disc Herniation: Results of Discectomy Compared With Those in Primary Herniation. Spine. 1999;24(8):800-806.

4. Cinotti G, Roysam GS, Eisenstein SM, Postacchini F. Ipsilateral recurrent lumbar disc herniation. A prospective, controlled study. J Bone Joint Surg Br 1998; 80:825-832.

5. Dai LY, Zhou Q, Yao WF, Shen L. Recurrent lumbar disc herniation after discectomy: outcome of repeat discectomy. Surgical Neurology. 2005; 64(3):226-231.

6. Erbayraktar S, Acar F, Tekinsoy B, Acar U, Güner EM. Outcome analysis of reoperations after lumbar discectomies: a report of 22 patients. Kobe $J$ Med Sci. 2002; 48 (1-2):33-41.

7. Fairbank J, Pynsent P. The Oswestry Disability Index. Spine. 2000; 25(22):2940-2953.

8. Fritsch EW, Heisel J, Rupp S. The Failed Back Surgery Syndrome: Reasons, Intraoperative Findings, and Long-term Results: A Report of 182 Operative Treatments. Spine. 1996; 21(5):626-633.

9. Fu TS, Lai PL, Tsai TT, Niu CC, Chen LH, Chen WJ. Long-term Results of Disc Excision for Recurrent Lumbar Disc Herniation With or Without Posterolateral Fusion. Spine. 2005;30(24):2830-2834.

10. Häkkinen A, Kiviranta I, Neva MH, Kautiainen H, Ylinen J. Reoperations after first lumbar disc herniation surgery; a special interest on residives during a 5-year follow-up. $B M C$ Musculoskeletal Disorders. 2007;8:2

11. Kara B, Tulum Z, Acar U. Functional results and the risk factors of reoperations after lumbar disc surgery. Eur Spine J. 2005;14(1):43-48.

12. Kayaoglu CR, Calikoglu C, Binler S. Re-operation after Lumbar Disc Surgery: Results in 85 Cases. The Journal of International Medical Research. 2003;31(4): 318-323.

13. Keskimaki I, Seitsalo S, Osterman H, Rissanen P. Reoperations After Lumbar Disc Surgery: A Population-Based Study of Regional and Interspecialty Variations. Spine. 2000; 25(12):1500-1508.

14. Kohlboeck G, Greimel KV, Piotrowski WP, Leibetseder M, Krombholz-Reindl M, Neuhofer R, Schmid A, Klinger R. Prognosis of multifactorial outcome in lumbar discectomy: a prospective longitudinal study investigating patients with disc prolapse.

15. Morgan-Hough CVJ, Jones PW, Eisenstein SM. Primary and revision lumbar discectomy. A 16-year review from one centre. J Bone Joint Surg Br. 2003;85-B (6):871-874.

16. Mullin WJ, Heithoff KB, Gilbert TJJr, Renfrew DL. Magnetic Resonance Evaluation of Recurrent Disc Herniation: Is Gadolinium Necessary? Spine. 2000; 25(12):1493-1499.

17. Osterman H, Sund R, Seitsalo S, Keskimaki I. Risk of Multiple Reoperations After Lumbar Discectomy: A Population-Based Study. Spine. 2003;28 (6):621-627.

18. Papadopoulos EC, Girardi FP, Sandhu HS, Sama AA, Parvataneni HK, O’Leary PF, Cammisa FP. Outcome of revision discectomies following recurrent lumbar disc herniation. Spine. 2006;31(13):1473-1476.

19. Phillips FM, Cunningham B. Managing chronic pain of spinal origin after lumbar surgery: the role of decompressive surgery. Spine. 2002; 27(22):2547-54.

20. Schoeggl A, Maier H, Saringer W, Reddy M, Matula C. Outcome After Chronic Sciatica as the Only Reason for Lumbar Microdiscectomy. Journal of Spinal Disorders\&Techniques 2002;15(5):415-419.

21. Skaf G, Bouclaous C, Alaraj A, Chamoun R. Clinical outcome of surgical treatment of failed back surgery syndrome. Surgical Neurology. 2005; 64(6):483-489

22. Slipman CW, Shin CH, Patel RK, Isaac Z, Huston CW, Lipetz JS, Lenrow DA, Braverman DL, Vresilovic EJ. Etiologies of failed back surgery syndrome. Pain Medicine. 2002;(3):200-214.

23. Suk KS, Lee HM, Moon SH, Kim NH. Recurrent lumbar disc herniation. Result of operative management. Spine. 2001; 26(6): 672-676.

24. Swartz KR, Trost GR. Recurrent Lumbar Disc Herniation. Neurosurg Focus. 2003; 15(3).

25. Toyone T, Tanaka T, Kato D, Kaneyama R. Low - Back Pain Following Surgery for Lumbar Disc Herniation: The Journal of Bone \& Joint Surg. 2004;86:893-896.

26. Wera GD, Marcus RE, Ghanayem AJ, Bohlman HH. Failure within One Year Following Subtotal Lumbar Discectomy. The Journal of Bone and Joint Surgery (Am). 2008; 90:10-15.

27. Yorimitsu E, Chiba K, Toyama Y, Hirabayashi K. Long-term outcomes of standard discectomy for lumbar disc herniation: a follow-up study of more than 10 years. Spine. 2001; 26(6):652-657. 